\title{
EMOTIONAL INTELLIGENCE AS A RELATED TO DIFFERENCE AREAS, STREAM' AND SEX' AMONG SCHOOL STUDENT
}

\author{
Dr. S. M. Makvana*
}

\begin{abstract}
This is the study was conducted as Emotional intelligence in the variables associated as a Types of area's (rural and urban), types of a streams (Arts and Science), and types of sex as a male and female. On a sample of 240 cases selected from secondary and higher secondary schools student's of Bharuch district of Gujarat state by rendering 2 × 2 × 2 three-factor factorial research design.

The emotional intelligence scale constructed and standardize by Patel and Patel 1985 was used to measured emotional intelligence.

The results reveal that's rural student are more emotional intelligence than urban school students are. In addition, emotional intelligence has be found to the greater in student of science stream compare to arts student and female student's as compare to a student of arts stream and male student's respectively.
\end{abstract}

\section{KEY WORDS}

Emotional intelligence, Areas (Rural and Urban) Sex's, (Male and Female) and Stream(Arts and Science)

\section{INTRODUCTION:}

We all have different personalities, different wants, different achievement, desire, needs, and different ways of showing our emotions. Navigating through this all takes tact and cleverness- especially if we hope to succeed in our life. This is where emotional intelligence becomes important. Mayer \& Salovey, (1997) both said "Emotional intelligence is the ability to perceive emotions, to access and generate emotions so as to assist thought, to understand emotions and emotional knowledge, and to reflectively regulate emotions so as to promote emotional and intellectual growth."

The present research aims to investigate the effect of Emotional intelligence with reference to types of area, Stream and types of Sex among Secondary and higher Secondary School Students. In the researcher research it was revealed that Student studding in secondary and higher secondary school in urban and rural area. They show different level of emotional intelligence, the School level variables directly related to the emotional intelligences. The research different variables were testing such as Self-awareness,

\footnotetext{
*Associate Professor, Department of Psychology, Sardar Patel University, Vallabhvidyanagar,
} GUJARAT-388120 
Management, Social skill \& consciousness, with understanding physical, mental health, performance at different work, and relationships of students. The School Student Proficiency, Competency, Temperament, and Character how to control them, he better able to express how to understand others feeling. In addition, other associated factors as principals reflected policies at the school. This is the ERA of competitive. Therefore, the student appears in competitive exam and some are not preparing for the exam so that created stressful environment around the whole behavior and enormous psychological stress on the school students.

Emotional intelligence is the ability to identify and manage your own emotions and the emotions of others. Mayer and Salovey (1993) "Emotional intelligence is a type of social intelligence that involves the ability to monitor one's own and other's emotions, to discriminate among them, and to use the information to guide one's thinking and actions." In contrast to Schutte et .al. (1998), Petrides and Furnham (2000), did not find a significant gender difference in overall trait of emotional intelligence. Other research as a find out in spite of the evidence that females seem to be more socially skilled than males by ARGYLE-(1990); Hargie, Saunders, \& Dickson-(1995), their self-estimated Emotional intelligence Scores tend to lower than those of males. They hypothesize possible explanations for this in terms of the nature and source of the bias by Male VS Female, these common attitudes color all aspects of classroom behavior creating a social behavior pattern or climate that appear to be stable once established. Thus 'climate' is as merely an abbreviated reference to those qualified that consistently predominates in most of teacherpupil contacts and contacts among the presence or absence of the teacher."The present researcher has used three Independent variables namely (A) Types of Area (Rural and Urban area), (B) Types of Stream (Arts and Science) and (C) Types of sex (Male and Female) to examine the effect on Emotional Intelligence.

\subsection{Components of Emotional Intelligence:}

Daniel Goleman (June-28-1999) following steps describes (The five components) of emotional intelligence:

1.1.1. Self-awareness: The ability to recognize and understand personal moods and emotions and drives, as well as their effect on others

1.1.2. Self-regulation: The ability to control or redirect disruptive impulses and moods, and the propensity to suspend judgment and to think before acting

1.1.3. Internal motivation: A passion to work for internal reasons that go beyond money and status -which are external, - such as an inner vision,. A propensity to pursue goals with energy and persistence

1.1.4. Empathy: An ability to understand the emotional makeup of other people, a skill in treating people according to their emotional reactions

1.1.5. Social skills: Proficiency in managing relationships and building networks, and ability to find common ground and build rapport

1.2. The key skill of Emotional Intelligence: Jeanne Segal, and Melinda smith (November2013) following Key skills steps describes of emotional intelligence:

1.2.1: Rapidly reduce stress in the moment: Be aware of your own feelings and needs, and communicate clearly. Being able to quickly calm yourself down and relieve stress helps you stay 
balanced, focused, and in control-no matter what challenges you face or how stressful a situation becomes.

1.2.2: Beat relationship stress with emotional awareness: Unfortunately, without emotional awareness, we are unable to understand our own motivations and needs, or to communicate effectively with others. Emotional awareness can be learning at any time of life. If you have not learned how to manage stress, it is important to do so first. When you can manage stress, you will feel more comfortable reconnecting to strong or unpleasant emotions and changing the way you experience and respond to your feelings.

1.2.3: Nonverbal communication: In order to hold the attention of others and build connection and trust, you need to be aware of, and in control of, this body language. You also need to be able to accurately read and respond to the nonverbal cues that other people send you. These messages do not stop when someone stops speaking. When you silent, and still communicating nonverbally. Think about what you are transmitting as well, and if what you say matches what you feel. If you insist, "I am fine," while clenching your teeth and looking away, your body is clearly signaling the opposite. Your nonverbal messages can produce a sense of interest, trust, excitement, and desire for connection-or they can generate fear, confusion, distrust, and disinterest.

1.2.4: Use humor and play to deal with challenges: Use humor and play to deal with challenges Humor, laughter, and play are natural antidotes to life's difficulties; they lighten your burdens and help you keep things in perspective. A good hearty laugh reduces stress, elevates mood, and brings your nervous system back into balance.

1.2.5: Resolve conflict positively: Conflict and disagreements are inevitable in relationships. Two people cannot possibly have the same needs, opinions, and expectations at all times. The ability to manage conflicts in a positive, trust-building way is support by the previous four skills of emotional intelligence.

\subsection{Model of Emotional intelligence:}

\begin{tabular}{|c|c|c|c|}
\hline \multirow{5}{*}{ 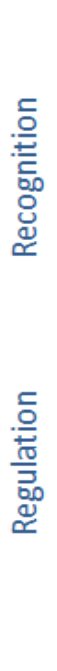 } & Self Awareness & Social Awareness & $\begin{array}{l}\text { 1.3.1. Self-awareness = You recognize your own } \\
\text { emotions and how they affect your thoughts and } \\
\text { behavior, know your strengths and weaknesses, } \\
\text { and have self-confidence. }\end{array}$ \\
\hline & $\begin{array}{l}\text { Self-Confidence } \\
\text { Emotional Self Awareness } \\
\text { Accurate Self Assessment }\end{array}$ & $\begin{array}{l}\text { Empathy } \\
\text { Organisational Awareness } \\
\text { Understanding the environment }\end{array}$ & $\begin{array}{l}\text { 1.3.2.Social awareness }=\text { You can understand } \\
\text { the emotions, needs, and concerns of other } \\
\text { people, pick up on emotional cues, feel } \\
\text { comfortable socially, and recognize the power } \\
\text { dynamics in a group or organization. }\end{array}$ \\
\hline & Self Management & Social Skills & $\begin{array}{l}\text { 1.3.3. Self-management }=\text { You're able to control } \\
\text { impulsive feelings and behaviors, manage your }\end{array}$ \\
\hline & Self-Control & Influence & $\begin{array}{l}\text { through on commitments, and adapt to changing } \\
\text { circumstances. }\end{array}$ \\
\hline & $\begin{array}{l}\text { Conscientiousness } \\
\text { Adaptability } \\
\text { Drive and motivation } \\
\text { Initiative }\end{array}$ & $\begin{array}{l}\text { Developing others } \\
\text { Influence } \\
\text { Building bonds } \\
\text { Team Work and Collaboration }\end{array}$ & $\begin{array}{l}\text { 1.3.4. Relationship management= You know } \\
\text { how to develop and maintain good relationships, } \\
\text { communicate clearly, inspire and influence } \\
\text { others, work well in a team, and manage } \\
\text { conflict. }\end{array}$ \\
\hline
\end{tabular}


The International Journal of Indian Psychology: Volume: 02 | Issue: 02 | February 2014
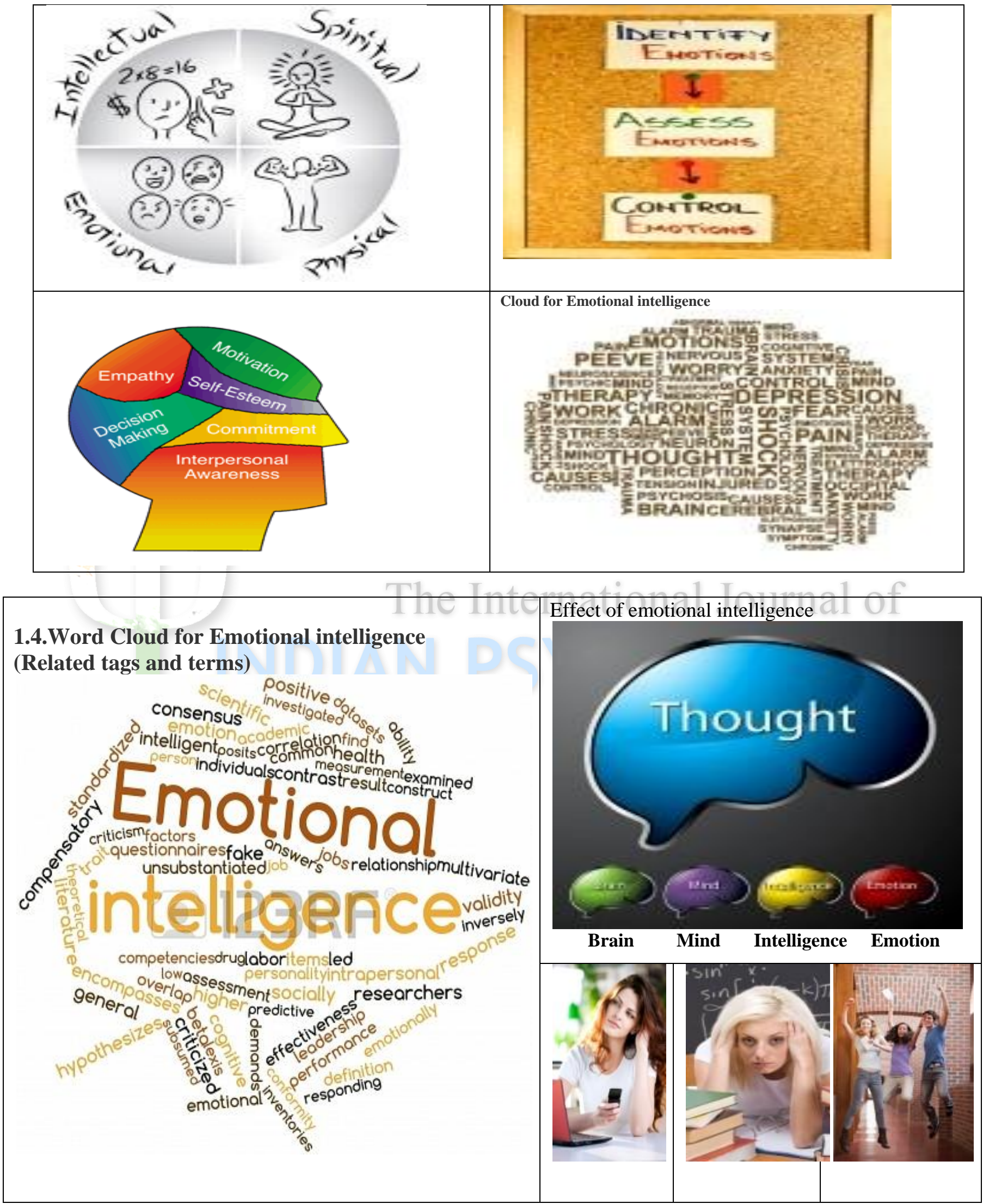
According to a CareerBuilder, employers are beginning to change what they look for in future candidates. Because the economy is under such uncertainty these days and companies are getting smaller, 34\% of hiring managers said they are placing greater emphasis on emotional intelligence when hiring and promoting employees post-recession. This blog post will give a summary of Jennifer Grasz's story. Emotional Intelligence or EI is an evaluation of person's ability to remain in control of their emotions, use their senses to understand and react to other individuals' emotions, and how deal with relations. This national survey conducted from May 19 to June 8, 2011 with more than 2,000 HR professionals and hiring managers. This assessment revealed that EI is a vital trait for getting a job. With these statistics, it is apparent that IQ is suddenly no longer important when it comes to hiring future employees $-75 \%$ said they would most likely promote the person with high EI.

\section{OBJECTIVES:}

In the present research, the role of Emotional intelligence among school student under the study been examined in the following context.

2.1. To investigate relationship between Emotional intelligence and types of area school student's

2.2. To examine the interactive effect of Emotional intelligence among Arts and Science stream school Student's

2.3. To examine the relative effects of Emotional intelligence among Male and Female school students

2.4. To study of relative effect of Emotional intelligence among Types of Area, Types of Stream and Types of sex typology.

\section{0: METHODOLOGY:}

\section{1: Sample:}

For the purpose of the present investigation, a sample consisting of 240,( In all) individual respondents were selected as a final sample from school going students of streams viz., Arts and Science, Area as a Rural and Urban and two levels of types of Sex were considered in the group of Male and female school students of Bharuch district of Gujarat state.

\section{2: Tools: following tools were used}

For the collection of the data, various research tools have, been used in the related studies. Researchers have collected the information regarding Emotional intelligence.

\subsection{1: Personal data sheet:}

For information (Dependents variables and Independent variables) Emotional intelligence regarding age, family, area, stream, sex, income source, type of work and so on were collected data/samples by Personal data sheet.

\subsection{2: Used of Scale:}

For the present investigation, the tool used were Emotional intelligence Scale having reliability of this tool Test Re-test method 0.89 and split-half method 0.85 . The scale consistd of 77- items on a 5 point scale ranging from "strongly agree" to "strongly disagree" with Four dimensions. realiability $\mathrm{r}=$ constructed and standardize by. Dr.P.P.Patel and Dr.H.P.Patel (1985) was used. 3.3: Hypotheses: Following major hypothesis tested in present research.

H1: There is no significant different between mean of the score on the Emotional intelligence of school student belonging to Rural and Urban area.

H2: There is no significant different between mean of the score on the Emotional intelligence regard Arts and Science school students

H3: There is no significant mean difference between the mean of the score on Emotional intelligence of school going Male and Female students. 
H4: There is no significant interactive relationship between Emotional intelligence and types of areas and stream of school students.

H5: There is no significant interactive effect on Emotional intelligence and types of area and Sex of school students.

H6: There is no significant interactive effect on Emotional intelligence and type of stream and Sex of school students.

H7: There is no significant interactive effect on emotional intelligence and type of Area, Stream and types of Sex of school students.

3. 4: Variable of the study:

3.4.1: Dependent variables: Total Scores of respondents on Emotional intelligence

3.4.2: Independent variables: Types of Area, Stream and Sex as a Independent variables.

3. 5: Research design: The $2 \times 2 \times 2$ three-factor factorial research design adopted in the study

Table No: 1:

Give about the Distribution of the cell wise Sample and means

\begin{tabular}{|l|l|l|l|l|l|}
\hline \multirow{2}{*}{$\begin{array}{l}\text { Variables and means } \\
\text { of emotional } \\
\text { intelligence }\end{array}$} & \multicolumn{1}{|c|}{ C1 $_{1}$} & C2 $_{2}$ & \multicolumn{2}{c|}{ C1 $_{1}$} & $\begin{array}{l}\text { Total Number } \\
\text { of sample }\end{array}$ \\
\hline A1 Mean score & 258.73 & 261.42 & 261.30 & 271.27 & \\
\hline Samples & 30 & 30 & 30 & 30 & $\mathbf{1 2 0}$ \\
\hline A2 Mean score & 246.60 & 260.10 & 260.60 & 256.73 & --- \\
\hline Samples & 30 & 30 & 30 & 30 & $\mathbf{1 2 0}$ \\
\hline Total & 60 & 60 & 60 & 6010 & $\mathbf{2 4 0}$ \\
\hline
\end{tabular}

A=Type of Area

A1=Urban

A2 $=$ Rural

$B=$ Type of Stream

B1=Science

$\mathbf{B}_{2}=$ Arts

C=Type of Sex

$\mathrm{C} 1=$ Male

$\mathrm{C}_{2}=$ Female

\section{6: Major statistical techniques used:}

To analyze the data with related variables of $2 \times 2 \times 2$ three-factor factorial research design and the 'ANOVA' applied in different variables.

\section{4.: RESULTS AND DISCUSSION:-}

The scores on Emotional Intelligence was analyzed as stated in three-factor factorial research design and basic satistics is as per below;

Table No.2:

The 2 X 2 X 2 Variables mean difference, ANOVA and L.S of Emotional Intelligence

\begin{tabular}{|l|l|l|l|l|l|}
\hline $\begin{array}{l}\text { Source } \\
\text { Variables }\end{array}$ & Sum of Squares & df & Mean ss & F-Value & $\begin{array}{l}\text { Level of } \\
\text { significance }\end{array}$ \\
\hline A=Area & 1983.75 & 1 & 1983.75 & 4.08 & 0.05 \\
\hline B=Stream & 3465.60 & 1 & 3465.60 & 7.13 & 0.01 \\
\hline C=Sex & 1870.42 & 1 & 1870.42 & 3.85 & 0.05 \\
\hline A X B & 1.67 & 1 & 1.67 & 0.003 & NS \\
\hline A X C & 385.07 & 1 & 385.07 & 0.79 & NS \\
\hline B X C & 84.02 & 1 & 84.02 & 0.17 & NS \\
\hline
\end{tabular}


The International Journal of Indian Psychology: Volume: 02 | Issue: 02 | February 2014

\begin{tabular}{|l|l|l|l|l|c|}
\hline & & & & & \\
\hline A X B X C & 1972.27 & 1 & 1972.27 & 4.05 & 0.05 \\
\hline SSW & 112868.47 & 232 & 486.50 & -- & -- \\
\hline Total & 16296748.00 & 240 & ---- & -- & -- \\
\hline
\end{tabular}

H 01: There is no significant mean difference between the mean of the score on the Emotional intelligence of school student belonging to Rural and Urban area.

Table No.1 and 2, indicates that the area play a crucial role in development of emotional intelligence. There are several urban and rural schools provide many facilities to the students and they may have good aspiration, expectation for betterment and active participation of school. It can be seen from Table no1 and 2, indicates that the mean score of students of rural area was $\mathrm{M}=262.48(\mathrm{~N}=120)$ and mean score of student of Urban was $=256.71(\mathrm{~N}=120)$, the difference between the 5.75. The Ho1 tested this observation. it was found that the (mean ss 1983.75) ' $F$ 'value is 4.08 for the types of area. which is significant at 0.05 level. Therefore the above, $\underline{\mathbf{H}}_{01}$ null-hypothesis was rejected and it was held that the students of Rural and Urban area school have shown difference in emotional intelligence. And this difference is found significant. The mean score of students of rural area is 262.48 while the mean score of students of urban area is 256.71. The $\mathrm{F}$ value is 4.08 for types of area. The difference is significant at 0.05 level, hence, the hypothesis is rejected. It means in the present study it is seen that there is a significant different in between students of rural and urban area. As per the scoring pattern the higher value of score indicates higher emotional intelligence. As can be seen, from the above table that the mean value of the students of rural area is higher than the students of urban area. Moreover, the difference is significant at 0.05 levels. Hence, it is seen that the emotional development among the students of rural area is more than the students of urban area. The probable reason for this kind of result may be that in rural area parents may be taking more care, may be more attentive to the children and may be having more concerned compared to urban area. In urban area parents are busy with business or their job hence may not be able to pay more attention on their children as a result they may not have developed more emotional intelligence compared to village students. The result supported by the research of Goleman (1995), validated this further by stating that in developing emotional intelligence "we learn how to feel about ourselves and how others will react to our feelings; how to think about these feelings and what choices we have in reacting; how to read and express hopes and fears". Along similar lines, another significant aspect that can explain this negative relationship is that of communication.

H2: There is no significant different between mean of the score on the Emotional intelligence of school students of Arts and Science Stream.

The results presented in table no, 1 and 2, indicate that the emotional intelligence of students in relation to stream of Science and Arts school students. There are several educational school institutions provided many facilities to the students and they may have good aspiration, expectation for betterment and active participation of school institution. It can be seen from above Table No.2 that the mean score of students of Arts stream was $255.80(\mathrm{~N}=120)$ and 
Science stream students was $263.40(\mathrm{~N}=120)$. Both group mean difference was 7.60. The $\mathbf{H ~} \mathbf{O}_{2}$ was tested above observation. it was found that the (mean ss 3465.60 ) ' $F$ 'value is $\underline{\mathbf{7 . 1 2}}$ for the types of stream which was significant at 0.01 level. Therefor the above, $\underline{\mathbf{H} 2}$ null-hypothesis was rejected and it was held that the students of Arts and Science stream have differences in emotional intelligence. And this difference is found significant. Hence, the hypothesis is rejected. It means in the present study it is seen that there is a significant different in between the students of Arts and Science stream. As per the scoring pattern the higher value of score indicates higher emotional intelligence and lower level score indicates lower level emotional intelligence. Harrington-Lueke(1997) found her research emotionally intelligence is just as importnant to success in life but no essential need. The people of high levels emotional intelligence he got more experience and career success, build stronger personal relationships, lead more effectively, and enjoy better health than those who people get low levels of emotional intelligence

H3: There is no significant mean difference between the mean of the score on Emotional intelligence of school going Male and Female students.

The objective of this research is to examine the relationship between emotional intelligence and sex as male and female school students. The results is presented and tested by Table no1 and two, which was indicates that the Mean scores of Male was 256.80 and Female was 262.39. The mean difference based on Sex variable was 5.58, with reference to emotional intelligence. In addition, the score was found significantly different. Hence, therefor the above, $\mathbf{H 3}$ nul-hypothesis was rejected and it was held that the Male and Female students of school show difference in emotional intelligence. (The result can be justify that the emotional intelligence a positive relationship of male and female) It can be seen from Table No.2, that the ' $F$ ' value of an emotional intelligence of Sex, was 3.85. It is seen that the mean ss is 1870.42 , and ' $F$ ' value was 3.85, which was significant at $\mathbf{0 . 0 5}$ levels. The focus of the above dependent and independents variables through formulated hypothesis and examination after found that the significant mean different between emotional intelligence is good relationship in the variables. As per the scoring pattern the higher value of score indicates higher emotional intelligence and lower level score indicates lower level emotional intelligence. The female students show higher emotional intelligence. The Probable reason may be that the girls gets mature earlier than boys. the girls are given special treatment in house regarding how to maintain the household, how to treat the guests and other visitors. Hence girls develop different kind of frame of reference regarding inter personal relations. this may lead to develop higher level of emotional intelligence compared to boys. The research supported to V.Dhoundiyal (1984), Parul Khanna (2003)

H4: There is no significant interactive relationship between Emotional intelligence and types of Area and Stream of school students

Looking to the above table number 1 and 2, indicates that it can observed that the interaction between Area and stream was not significant variables. The Mean of area as a 259.61 and stream variables mean was 259.60 and variables mean differences was 0.01 , it was found that the mean ss 1.67 and ' $F$ ' value is 0.00 . The ' $F$ ' value was not significant at any level. Therefor the above, 
$\underline{\mathbf{H}}_{4}$ null-hypothesis was accepted. The interactive effect between A x B variable was not significant.

Hs: There is no significant interactive effect on Emotional intelligence of types of Area and Sex of school students

Looking to the above table number 1 and 2, indicates that, it can be observed that the interaction between types of Area and Sex, the mean of Types of area variables is 259.61 and Types of Sex variables mean was 259.60 and variables mean differences was 0.01 , it was found that the mean ss 385.07 and ' $F$ ' value is 0.79 . The ' $F$ ' value was not significant at any level. Therefor the above, $\mathbf{H}_{5}$ null-hypothesis was accepted. The interactive effect of (A X B) was not found significant.

H6: There is no significant interactive difference between type of stream and Sex of school students regarding Emotional intelligence.

Looking to the above table number 1 and 2, it can be observed that the interaction between types of Stream and Sex. The Types of Stream variables Mean was 259.60 and Types of Sex variables mean score was 259.60. The independent both variables mean differences found the 0.00. It was found that the mean ss 84.02 and ' $F$ ' value is 0.17 . The ' $F$ ' value was not significant.Therefor the above, $\mathbf{H}_{\mathbf{6}}$ null-hypothesis was accepted. The interactive effect of (B X C) was not found significant.

H7: There is no significant interactive effect on emotional intelligence of type of Area, Stream and types of Sex of school students.

It is observed that the table number 1 and 2, indicates that the second order interaction as well as (A X B X C) results are presented and tested the above hypothesis. It was found that the mean ss 1972.27 and ' $F$ ' value was 4.05 , which was significant at 0.05 levels. Therefor the abov e, $\mathbf{H}_{7}$ null-hypothesis was rejected and it was held that the students of Area, Stream and Sex and this difference was found significant. From the result it is seen that the difference is significant at 0.05 levels. Hence, it is seen that the emotional development among the students of rural area is more than the students of urban area. The probable reason for this kind of result may be that in rural area, parents may be taking more care, may be more attentive to the children and may be having more concerned compared to urban area. In urban area parents are busy with business or their job hence may not be able to pay more attention on their children as a result they may not have developed more emotional intelligence compared to village students..

\subsection{Conclusions:}

Following conclusions have been drawn from the present study,

* The students of rural area have shown more emotional intelligence compared to students of urban area.

* The student of science stream are found having more emotional intelligence compared to arts students

* The girls of both the stream are found having more emotional intelligence compared to boys. 
* The Area, Stream and Sex variables seen that there is significant interaction among emotional intelligence. The variables of $\mathrm{A}$ x $\mathrm{B}$ x C respondents with regard and highly respected with developing to the emotional intelligence as a school level variables. Emotional intelligence is a significant interactive relationship between above (A $\mathbf{x} B \times$ C) three independent variables.

5.2.Limitations Of The Study:-Following are the limitations of the present study

$>$ The sample was drawn from Gujarat State hence it can be not applicable to whole India.

$>$ The sample was drawn from two Streams namely Arts and Science, other stream is not included.

$>$ The institutions like higher primary school std. 8 and primary school, military school, colleges and disable school student are not included.

$>$ While selecting the sample religion is not taken in to consideration, so religion wise difference cannot be inferred from the data.

5.3.Suggestion For Further research:-Following are the suggestion for further study

- For comprehensive study all types of schools may be included in the study so as to remove school biases, Sample included state wise areas also remove effect of areas.

\subsection{Implication Of The Study:}

- A profile of the urban and rural area school students may be prepared to solve the problem of emotional intelligence and to develop the group of students.

- The impact of emotional intelligence can be predicted with the help of results and can be manipulated effectively to get better results with respect to self and social-awarenessmanagement, and social skills.

- The students having less emotional intelligence may traced out and can be given intensive training to increase emotional intelligence.

\section{READINGS:}

\section{Books:}

(1) Mayer J.D., and Salovey, P.(1993) ; The intelligence of emotional intelligence. Intelligence, 17, 433-444

(2) Mayer J.D., and Salovey, P.\& Caruso, D.R.(2002) ; Emotional intelligence test (MSCEIT) Verson 2. Toronto, on Multi-Health System 
The International Journal of Indian Psychology: Volume: 02 | Issue: 02 | February 2014

\section{Journals:}

(1) Shah Mukti and Nutankumar: JIAAP- ISSN-0019-4247-January2008, vol, 34 No.1, 83-91

(2) Bhattacharya \&V.Vijayalakshmi: JIAAP-ISSN-0019-4247-January2008, vol 34 No.1, 93-100 Website:

(1) http://en.wikipedia.org

(2) http://www.edge.org

(3) http://www.eiconsortium.org/

(4) http://www.google.co.in

(5) http://www.helpguide.org

(6) http://www.maetrix.com.au

(7) http://www.unh.edu 